\title{
Identification of Lymphotoxin and Tumor Necrosis Factor in Multiple Sclerosis Lesions
}

\author{
Krzysztof Selmaj, Cedric S. Raine, Barbara Cannella, and Celia F. Brosnan \\ Albert Einstein College of Medicine, Department of Pathology (Neuropathology), Bronx, New York 10461
}

\begin{abstract}
Multiple sclerosis (MS) brain tissue, spleen, and PBMC were studied using immunocytochemistry and FACS $^{\circledR}$ for immunoreactivity for lymphotoxin (LT) and TNF. Both cytokines were identified in acute and chronic active MS lesions but were absent from chronic silent lesions. LT was associated with $\mathrm{CD3}^{+}$ lymphocytes and Leu-M5 ${ }^{+}$microglia cells at the lesion edge and to a lesser extent, in adjacent white matter. TNF was associated with astrocytes in all areas of the lesion, and with foamy macrophages in the center of the active lesion. In acute lesions, immunoreactivity for TNF in endothelial cells was noted at the lesion edge. No LT or TNF reactivity was detected in Alzheimer's or Parkinson's disease brain tissues but was present at lower levels in central nervous system (CNS) tissue from other inflammatory conditions, except for adrenoleucodystrophy which displayed high levels of LT in microglia. No increase in LT and TNF reactivity was detected in spleen and PBMC of MS patients suggesting specific reactivity within the CNS. These results indicate that LT and TNF may be involved in the immunopathogenesis of MS, and can be detected in both inflammatory cells and cells endogenous to the CNS. ( J. Clin. Invest. 1991.87:949-954.) Key words: cytokines • demyelination • glial cells • lymphocytes $\bullet$ central nervous system
\end{abstract}

\section{Introduction}

Multiple sclerosis (MS) ${ }^{1}$ is a disease of the central nervous system (CNS) that is characterized pathologically by areas of primary demyelination in the vicinity of a mononuclear cell perivascular inflammatory reaction. Although the etiology of the disease remains unknown, studies from various animal model systems strongly support the notion that cell-mediated immune reactions against myelin antigens contribute to the disease process (1). However, the mechanism by which a cell-mediated immune response might lead to myelin damage remains to be defined.

Address correspondence and reprint requests to Dr. Krzysztof Selmaj, Albert Einstein College of Medicine, Department of Pathology, 1300 Morris Park Avenue, New York, NY 10461.

Received for publication 25 June 1990 and in revised form 28 September 1990 .

1. Abbreviations used in this paper: $\mathrm{ABC}$, avidin biotin complex; $\mathrm{ALD}$, adrenoleucodystrophy; DAB, 3,3'-diaminobenzidine; GFAP, glial fibrillary acidic protein; LT, lymphotoxin; MS, multiple sclerosis; SSPE, subacute sclerosing panencephalitis; TSP, tropical spastic paraparesis.

J. Clin. Invest.

(c) The American Society for Clinical Investigation, Inc.

0021-9738/91/03/0949/06 \$2.00

Volume 87, March 1991, 949-954
Recently, studies both in vivo and in vitro have implicated a role for the cytotoxic cytokine, TNF, in the pathology of the primary demyelinating diseases. In MS lesions, immunoreactivity for TNF has been reported in association with astrocytes and macrophages (2), and a potential role for TNF in the demyelinating process has been suggested by reports from this laboratory that TNF is cytotoxic for oligodendrocytes in culture and induces a delayed onset degradation of myelin in organotypic cultures of nervous tissue (3). Further studies (unpublished observation), however, have indicated that oligodendrocytes are even more sensitive to the highly homologous cytokine, lymphotoxin (LT), but to date, no studies have addressed the potential involvement of LT in MS lesions. In this report, we present data that show the presence of immunoreactivity for LT in active MS lesions in association with both lymphocytes and cells endogenous to the CNS.

\section{Methods}

Tissue samples. Early $(<6 \mathrm{~h})$ postmortem material was obtained from 14 MS cases. 1-4 blocks with MS plaque(s) and adjacent white matter were studied from each case. 2 groups of controls were used: 3 CNS tissue samples from patients who died of nonneurological diseases and without pathologic changes within the CNS, and 7 CNS tissue samples from patients who died with other neurological diseases: 3 with Alzheimer's disease; 1 with Parkinson's disease; 1 with tropical spastic paraparesis (TSP); 1 with subacute sclerosing panencephalitis (SSPE), and 1 with adrenoleucodystrophy (ALD). Spleen tissue was obtained from 3 of the MS cases and 2 normal patients. Tissue obtained during autopsy was embedded in optimal cooling temperature compound (Miles Laboratories Inc., Elkhart, IN) and stored at $-70^{\circ} \mathrm{C}$.

Immunocytochemistry. Acetone-fixed frozen sections were stained using the avidin-biotin-peroxidase-complex technique (ABC; Vector Laboratories, Inc., Burlingame, CA) (4). Briefly, sections were air dried for $60 \mathrm{~min}$ and then fixed in acetone for $10 \mathrm{~min}$ at $4^{\circ} \mathrm{C}$. After blocking with $0.03 \%$ hydrogen peroxide and serum, the sections were incubated with primary antibody overnight at $4^{\circ} \mathrm{C}$ at the appropriate dilution. Secondary biotinylated antibody (horse anti-mouse IgG or goat antirabbit IgG) was applied for $60 \mathrm{~min}$ at room temperature followed by the $\mathrm{ABC}$ reagent for another $60 \mathrm{~min}$. 3,3'-diaminobenzidine (DAB) (Dako Corp., Carpinteria, CA) was used as a chromogen. Some sections were counterstained with hematoxylin. For double staining, antiglial fibrillary acidic protein (GFAP), anti-CD3, anti-LeuM5, or Ulex were used with the $\mathrm{ABC}$ technique with $\mathrm{DAB}$ and $\mathrm{NiCl}_{2}$ as the chromogen, which yielded a blue reaction product to contrast with the brown DAB color. Controls consisted of normal rabbit serum and omission of the primary antibody. Frozen sections of spleen tissue were used as a positive control for cytokine reactivity.

Antibodies. The following mono- and polyclonal antibodies were used for immunocytochemical staining and for FACS ${ }^{\circledR}$ analysis: mouse MAb against human CD3 (1:100; Becton Dickinson \& Co., Mountain View, CA), MAb against human TNF (1:50; Olympus Corp., Lake Success, NY), polyclonal rabbit anti-human TNF (1:100; Genzyme Corp., Boston, MA), MAb against human LT (1:2; Boerhinger Mannheim Inc., Indianapolis, IN), rabbit polyclonal anti-human LT (1:100; Genzyme Corp.), polyclonal rabbit anti-human GFAP (1:200; gift of 
Dr. J. Goldman, Columbia University, NY), mouse monoclonal antiLeuM-5 (1:5; Becton Dickinson \& Co.), Ulex (1:100; Europaeus agglutinin, Vector Laboratories, Inc.). According to the information provided by the vendors, the antibodies to LT and TNF did not show cross-reactivity with each other or with other cytokines.

Peripheral blood mononuclear cell isolates. 14 MS patients, 12 with chronic progressive disease and 2 with remitting relapsing disease, were used for $\mathrm{FACS}^{\oplus}$ analysis. All patients were in a clinically active period of disease at the time of study. Diagnosis of MS included magnetic resonance imaging and fulfilled accepted diagnostic criteria for MS (5). 8 controls consisting of healthy volunteers of similar age and sex distribution as the MS patients were assayed. Blood was withdrawn from the cubital vein directly into Leuco Prep cell separation tubes (Beckton Dickinson \& Co.) and centrifuged at $1,600 \mathrm{~g}$ at room temperature.

Immunofluorescent staining and FACS analysis. PBMC isolated from MS patients and control subjects were stained by an indirect immunofluorescence method. Briefly, $1 \times 10^{6}$ cells per sample were incubated with primary unlabeled $\mathrm{mAb}$ against $\mathrm{LT}$ and TNF for 60 min at room temperature, followed by goat anti-mouse IgG conjugated with fluorescein, diluted 1:20 for another $60 \mathrm{~min}$. After $2 \times$ washing in PBS, cells were analyzed using the FACS ${ }^{\oplus}$.

\section{Results}

Morphology of $\mathrm{LT}^{+}$and $\mathrm{TNF}^{+}$cells in MS lesions. Cells that showed positive immunoreactivity for LT presented with two types of morphology (Fig. 1). The first type was lymphocytelike (Fig. $1 A$ ) and the second type had a microglia-like morphology (Fig. $1 B$ ). Lymphocyte reactivity for LT was confirmed using a double-staining procedure with anti-CD3 antibody (Fig. $1 C$ ) and microglial reactivity for $\mathrm{LT}$ was confirmed using a double-staining procedure with anti-LeuM-5 antibody (Fig. $1 D$ ).

The $\mathrm{TNF}^{+}$cells in MS plaques presented with three types of morphology (Fig. 2). The majority of these had an astrocytelike morphology (Fig. $2 A$ ) and astrocyte reactivity for TNF was confirmed in a double-staining procedure with anti-GFAP antibody (Fig. $2 \mathrm{~B}$ ). However, $\mathrm{TNF}^{+}$immunoreactivity was not detected in the astrocytic perivascular endfeet. The second type had the morphology of foamy macrophages (Fig. $2 C$ ) and this was confirmed by double staining with anti-LeuM-5. The third type was endothelial cells. This staining of endothelial cells was rare but could be distinguished from $\mathrm{TNF}^{+}$, LeuM- $5^{+}$macrophages occasionally present in the perivascular cuffs (Fig. 2 D). Endothelial cell staining was confirmed by double staining with Ulex (data not shown). In Alzheimer's and Parkinson's disease brain tissue, no $\mathrm{LT}^{+}$or $\mathrm{TNF}^{+}$cells were identified in any of the sections. In three other conditions with an inflammatory component (TSP, SSPE, and ALD), a lower level of TNF reactivity than in MS tissue was present in inflammatory cells in all cases. However, positive reactivity for LT was only noted in SSPE and in occasional inflammatory cells in ALD. Microglia were strongly positive for LT in ALD, showed very weak reactivity for LT in SSPE, and were negative for LT in TSP. Astrocytes were occasionally weakly positive for TNF in TSP, ALD, and SSPE, with reactivity associated primarily with cell processes rather than the cell body.

$\mathrm{LT}^{+}$and $\mathrm{TNF}^{+}$cells in MS lesions and correlation with lesion activity: $\mathrm{LT}^{+}$cells were identified in 44/63 lesions (11/14 MS cases), and $\mathrm{TNF}^{+}$cells in $41 / 63$ lesions ( $12 / 14$ cases). To define the distribution of these cells in MS tissue, the lesions were classified into three categories: acute, chronic active, and chronic silent, according to accepted criteria of the extent and intensity of the inflammatory cell infiltrates (6).

Acute $\mathrm{MS}$ plaques. $\mathrm{LT}^{+}$and $\mathrm{TNF}^{+}$cells were identified in all acute plaques studied (Table I). $\mathrm{LT}^{+}$cells were located primarily at the lesion edge with $\mathrm{LT}^{+}$lymphocytes clustered in perivascular cuffs and $\mathrm{LT}^{+}$microglia distributed along the border of the demyelinated lesions and in the surrounding adjacent white matter. In contrast, $\mathrm{TNF}^{+}$immunoreactivity could be detected in all areas of the lesion (Table I). In the lesion center, this immunoreactivity was primarily localized to foamy macrophages. At the lesion edge and in adjacent white matter, $\mathrm{TNF}^{+}$immunoreactivity was localized in astrocytes. $\mathrm{TNF}^{+}$reactivity in endothelial cells was detected only in acute lesions and only at the lesion edge.

Chronic active plaques. $\mathrm{LT}^{+}$and $\mathrm{TNF}^{+}$cells were also identified in all chronic active plaques examined (Table $\mathrm{I}$; and see below). $\mathrm{LT}^{+}$lymphocytes were detected in perivascular cuffs at the lesion edge. $\mathrm{LT}^{+}$microglia were also present at the lesion edge but positive immunoreactivity in adjacent white matter was not as prominent as in acute lesions. In the lesion center, $\mathrm{TNF}^{+}$astrocytes and $\mathrm{TNF}^{+}$macrophages were present in substantial numbers. $\mathrm{TNF}^{+}$astrocytes were also numerous at the lesion edge, and occasionally occurred in adjacent white matter.

Chronic silent plaques. No $\mathrm{LT}^{+}$lymphocytes were detected in chronic silent plaques. Only occasional microglia showed positive immunoreactivity for LT at the lesion edge and in adjacent white matter (Table I). $\mathrm{TNF}^{+}$cells were rare and consisted only of occasional foamy macrophages.

Quantitation of $\mathrm{LT}^{+}$and $\mathrm{TNF}^{+}$cells in MS lesions. To define more accurately the distribution of immunoreactivity for LT and TNF, different cell types were counted in different areas of chronic active lesions (Fig. 3). Chronic active lesions were chosen for these studies because the different areas of the lesion can be easily defined and inflammatory cells are numerous. The data show that in $\mathrm{CD}^{+}$lymphocytes at the edge of the lesion and in adjacent white matter, 90 and $85 \%$, respectively, reacted with anti-lymphotoxin antibodies. In the center of the lesion, however, only $37 \%$ of the $\mathrm{CD}^{+}$lymphocytes showed LT immunoreactivity. In Leu-M5 ${ }^{+}$microglia at the lesion edge and in adjacent white matter, the numbers were 75 and $40 \%$, respectively, for $\mathrm{LT}^{+}$immunoreactivity. In the lesion center, no typical microglia were detected and Leu-M5 ${ }^{+}$immunoreactivity was associated with foamy macrophages. In these cells, 93\% reacted positively with antibodies to TNF. No foamy macrophages were detected outside the lesion center. In GFAP ${ }^{+}$ astrocytes, immunoreactivity for TNF was identified in all areas of the lesion with $24.5 \%$ positive in the lesion center, $45 \%$ positive at the lesion edge, and $20 \%$ positive in the adjacent white matter.

$\mathrm{LT}^{+}$and $\mathrm{TNF}^{+}$cells in MS and normal spleen. The occurence of mononuclear cells that showed positive immunoreactivity for LT and TNF was infrequent and did not differ in spleen from patients with MS from that found in control spleen. There was no evident overlap between $\mathrm{TNF}^{+}$and $\mathrm{LT}^{+}$cells in MS and normal spleen.

$\mathrm{LT}^{+}$and $\mathrm{TNF}^{+}$cells in peripheral blood mononuclear cells. To assess the potential reactivity of PBMC for these cytokines, 14 MS patients and 8 controls were studied by FACS $^{\circledR}$ analysis. All MS patients were defined as clinically active at the time of study. The percentage of PBMC of MS patients that reacted with anti-LT antibodies was almost exactly the same as in con- 

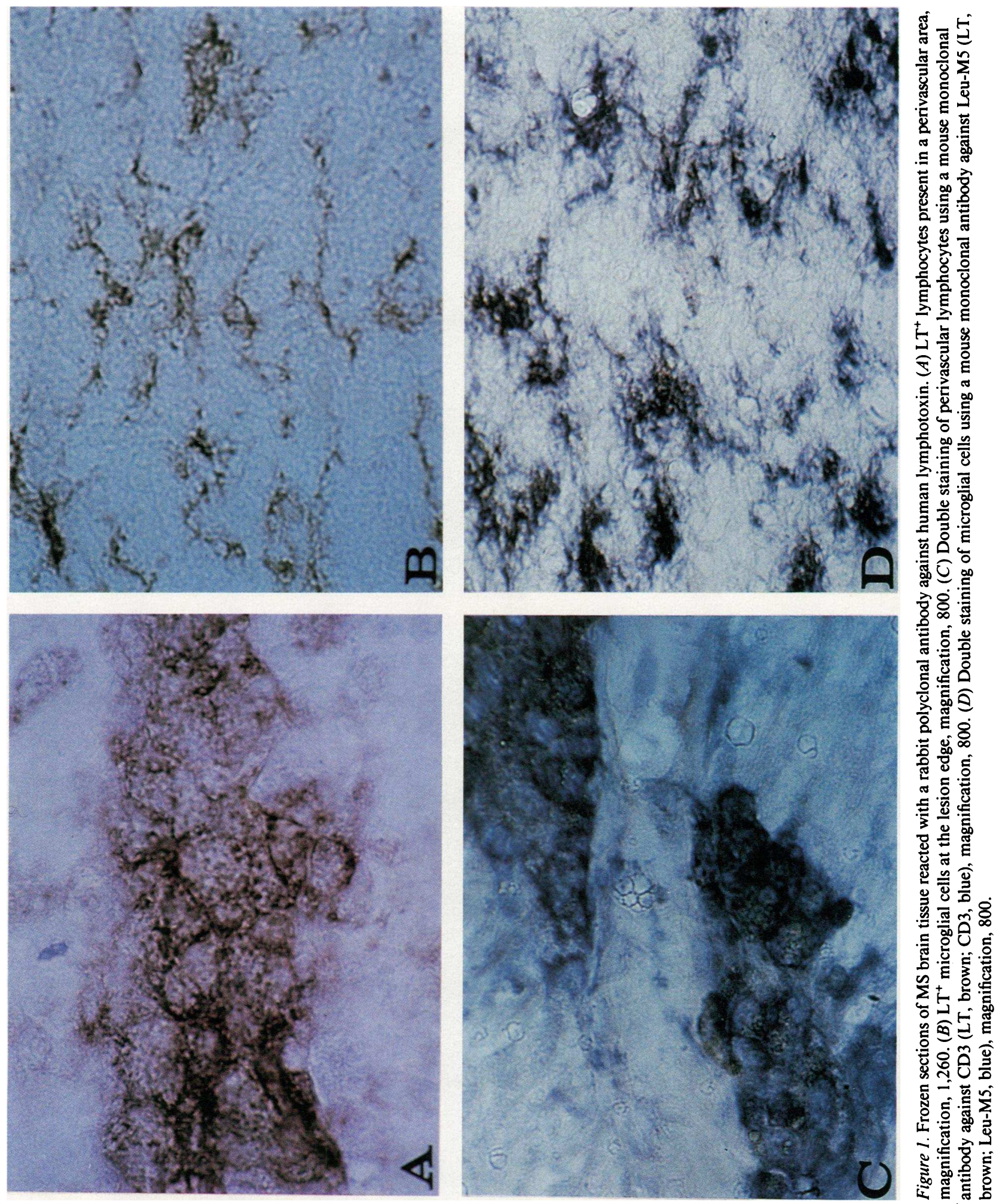

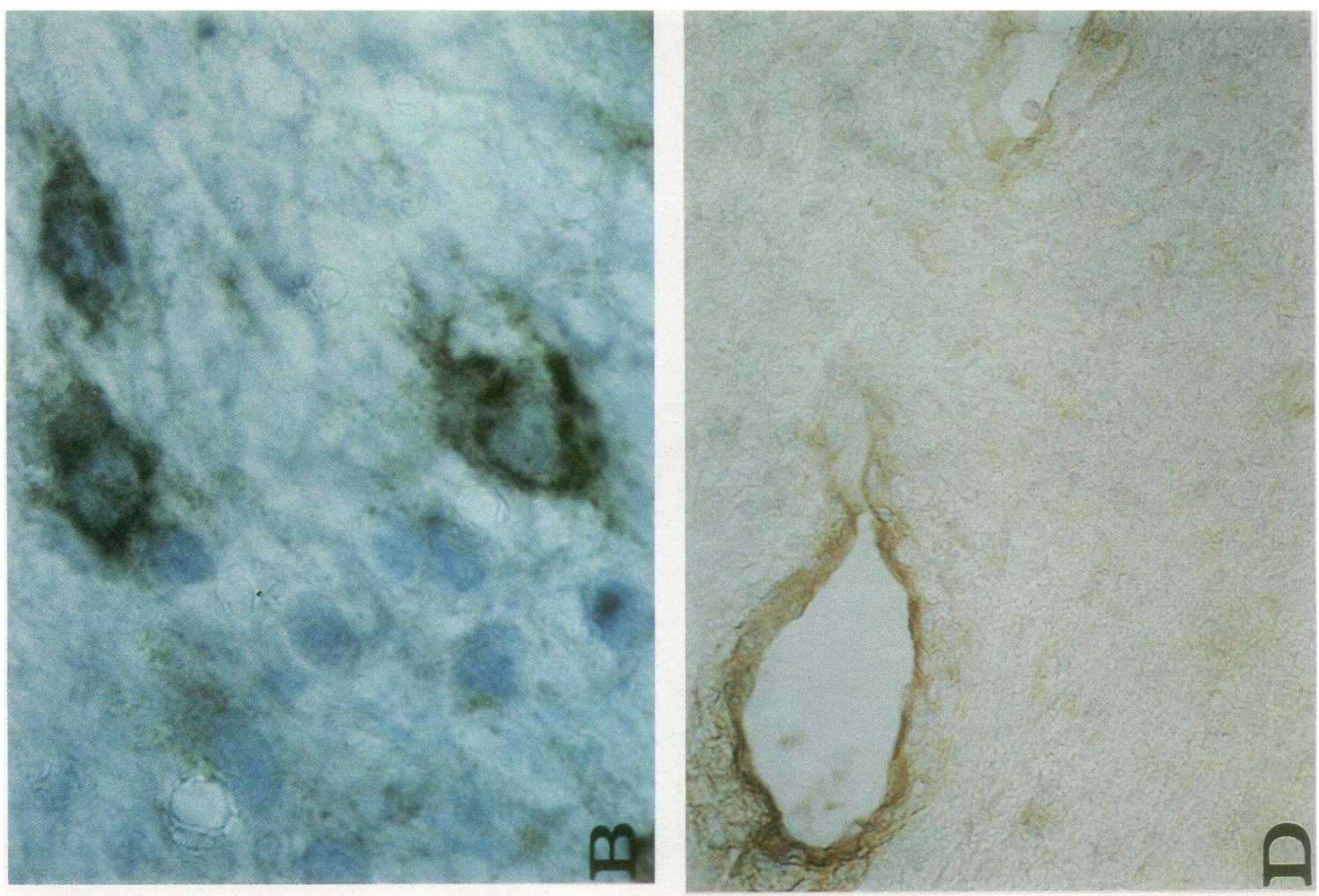

空古 웡 ठ̊용

क

造.

응

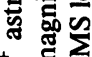

崖苛

吾

ड्र

定

岕嵒

क

잉 항

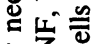

는

要

这

동 훙

要

ড苋

喿 중 륭
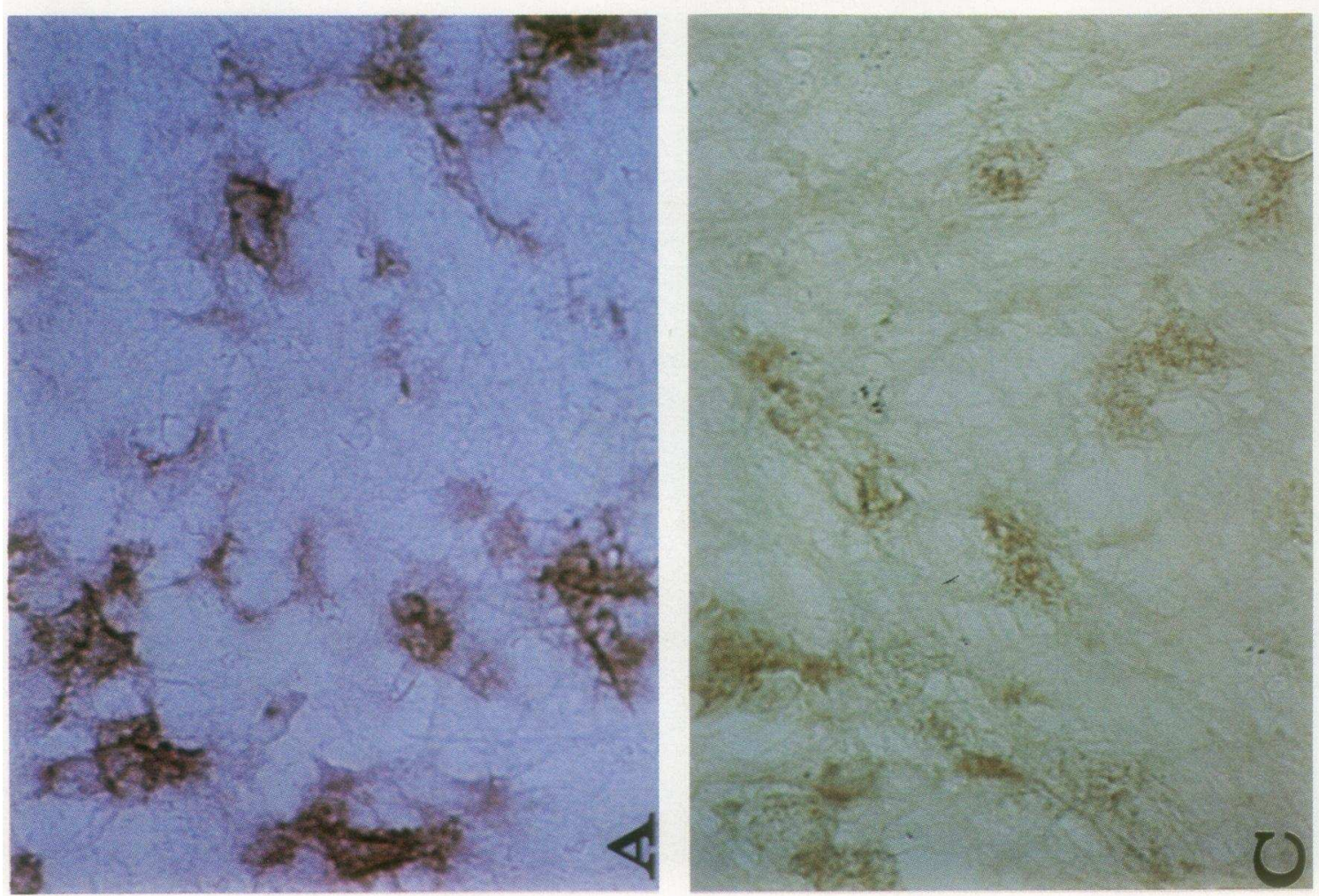

중을 젱

葛艺艺

을

응혈

5.

용.

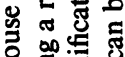

을

๙

势

过

\%

等

岁.

要.

की के

ㅇㅎㅎ

응

政

ธ

ธิ

实象

记

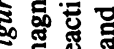


Table I. Distribution of LT and TNF Reactivity within MS Lesions

\begin{tabular}{|c|c|c|c|c|c|c|}
\hline \multirow[b]{3}{*}{ Type of lesion } & \multicolumn{6}{|c|}{ Localization } \\
\hline & \multicolumn{2}{|c|}{ Center } & \multicolumn{2}{|c|}{ Edge } & \multicolumn{2}{|c|}{$\begin{array}{l}\text { Adjacent white } \\
\text { matter }\end{array}$} \\
\hline & LT & TNF & LT & TNF & $\mathbf{L T}$ & TNF \\
\hline $\begin{array}{l}\text { Acute } \\
\qquad(n=19)\end{array}$ & - & 8 & 19 & 17 & 17 & 14 \\
\hline $\begin{array}{l}\text { Chronic active } \\
(n=20)\end{array}$ & - & 12 & 20 & 19 & 20 & 18 \\
\hline $\begin{array}{l}\text { Chronic silent } \\
\quad(n=24)\end{array}$ & - & 3 & 5 & - & 5 & - \\
\hline
\end{tabular}

trols $(2.45 \% \pm 0.8$ vs. $2.87 \% \pm 1.4 ; P>0.05)$. The percentage of $\mathrm{TNF}^{+}$cells in PBMC of MS patients was slightly but insignificantly higher than in controls $(4.44 \% \pm 1.1$ vs. $2.6 \% \pm 1.6 ; P$ $>0.05$ ). Although these results were generated from a different group of MS patients than those studied by immunohistochemistry of CNS tissue, they suggest that disease activity is not associated with increased reactivity of PBMC for LT and TNF.

\section{Discussion}

The results of this study provide, for the first time, evidence that LT is present in MS lesions. The presence of LT was associated with acute and chronic active plaques suggesting its involvement in lesion formation. The highly homologous cytokine, TNF, was also detected in MS lesions of similar activity. These cytokines could be identified using either polyclonal or monoclonal antibodies to both cytokines but reactivity was always more intense with the polyclonal antibodies. Reactivity was noted principally with cells at the edge of the lesions, but showed different patterns of cellular localization. Antibodies to LT reacted with $\mathrm{CD}^{+}$lymphocytes and microglial cells, whereas antibodies to TNF reacted with astrocytes and foamy macrophages in active lesions, and infrequently with endothelial cells at the lesion edge in acute lesions. Quantitation of $\mathrm{LT}^{+}$ and $\mathrm{TNF}^{+}$cells in the spleen and peripheral blood by immunocytochemistry and FACS $^{\circledR}$ analysis demonstrated no elevation in the number of these cells in MS, suggesting that the activation of inflammatory cells to express LT and TNF occurs locally within the target organ, the CNS.

Consistent with the low TNF immunoreactivity in PBMC, are reports of undetectable levels of TNF in serum and CSF from patients with MS, regardless of the extent of clinical activity $(7,8)$. However, two studies have reported increased production of TNF by macrophages isolated from peripheral blood and cerebrospinal fluid of MS patients after activation with lipopolysaccharide and phorbol myristate acetate (9), or concanavalin A and phytohemagglutinin (10). Unstimulated cells showed no TNF reactivity. The experiments of Merrill et al. (9) did not address a correlation with disease activity, but in the studies of Beck et al. (10), this increased production of TNF after stimulation was only detected immediately before and during clinical exacerbation.

The presence of TNF immunoreactivity in astrocytes in MS is in agreement with the observations of Hofman et al. (2), where $\mathrm{TNF}^{+}$astrocytes were detected at the lesion edge. Al-
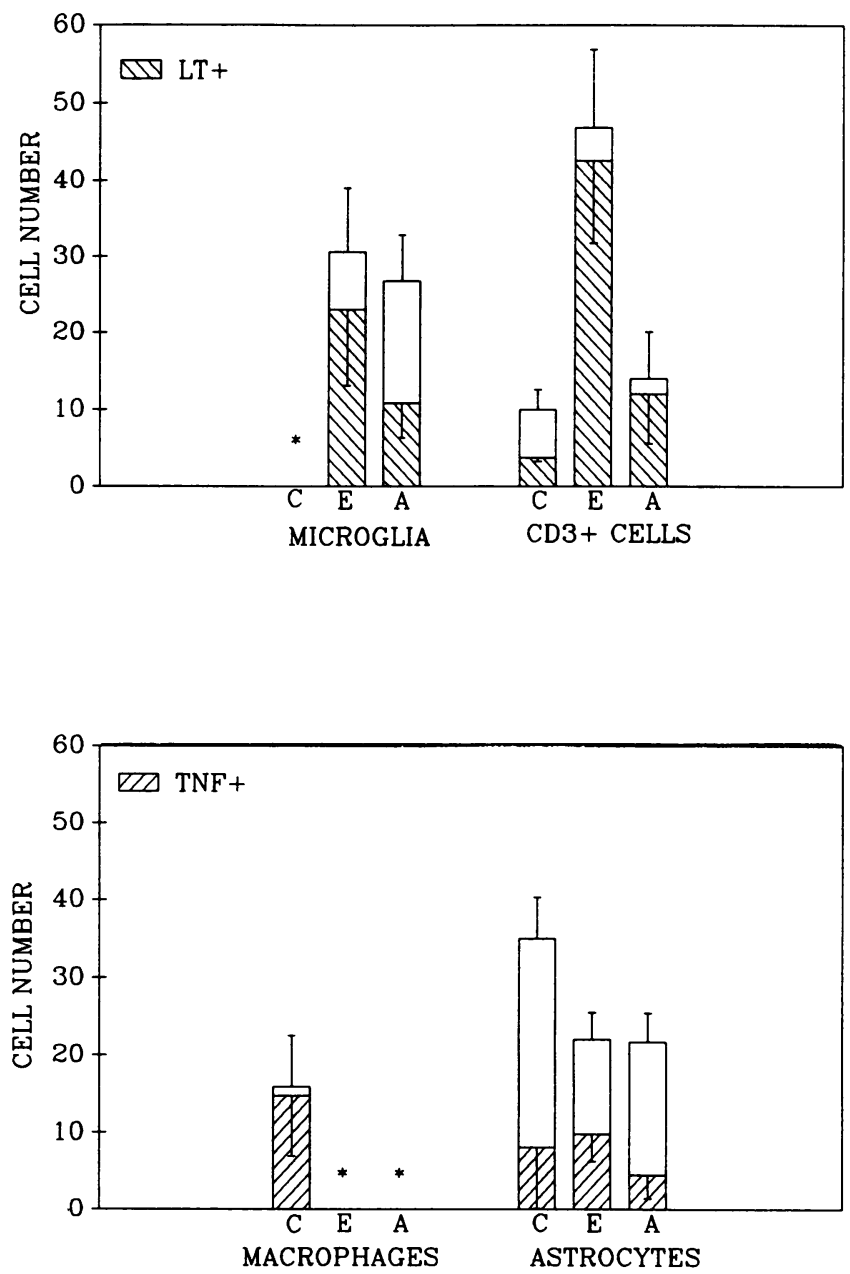

Figure 3. Histograms of the number of cells $/ 0.07 / \mathrm{mm}^{2}$ within chronic active lesions. Open bars represent the mean number of each cell type $\pm \mathrm{SD}$ counted in different areas of several lesions $(C$, center; $E$, edge; $A$, adjacent white matter) and the hatched bars represent the mean number of cells \pm SD that show positive immunoreactivity for LT (top) and for TNF (bottom). *Areas in which no cells of that particular type were detected.

though positive cytokine immunoreactivity does not prove that these cells manufacture TNF, two recent reports have documented TNF production by astrocytes in culture $(11,12)$. Taken together, these data strongly suggest that astrocytes can be activated to produce TNF in situ in MS lesions. Occasional weak reactivity for TNF in astrocytes was also noted in other CNS inflammatory conditions.

In vitro studies also suggest that astrocytes and microglia can be activated to produce $\mathrm{LT}(11,13)$. The parameters of LT production by microglia have not been well studied. However in astrocytes, significant differences in TNF and LT have been reported depending upon the nature of the activating signals in that production of LT was only detected in response to a neurotropic paramyxovirus, whereas TNF was produced in response to lipopolysaccharide (11). A similar observation has been made in human peripheral blood lymphocytes where mitogen stimulation primarily induced LT, and phorbol diester and calcium ionophore-induced TNF (14). These results suggest that the genes encoding LT and TNF may be independently acti- 
vated. Since we detected LT and TNF in different populations of CNS glial cells, it is interesting to speculate that further studies in this area might contribute to the elucidation of the pathogenesis of MS. Interestingly, strong reactivity for LT in microglia was also detected in ALD, but these cells were essentially negative for LT in TSP and SSPE.

LT and TNF are cytokines with pleiotropic activity $(15,16)$ and have frequently been associated with different types of inflammation and autoimmunity. Both LT and TNF can behave as effector as well as regulatory proteins. They are directly cytotoxic for various tumor cell lines (17), destroy pancreatic islet cells (18), and actively mediate bone resorption (19). LT and TNF can interact with endothelial cells and activate the endothelium of postcapillary venules. As a consequence of this, enhanced lymphocyte adhesion (20), increased expression of adhesion molecules such as ICAM-1 (21), and increased permeability (22) have been reported. LT and TNF activate monocytes $(23,24)$ and in this way, may perpetuate the immunopathological process. LT and TNF can also induce the synthesis of other cytokines (25) and may thus orchestrate the cytokine network in the immune response.

Additional studies have shown that TNF and LT are mitogenic for astrocytes (26) and TNF is mitogenic for astrocytoma cells lines in vitro (27). Thus, TNF (and to a lesser extent, LT) may function as an autocrine growth factor for astrocytes. However, astrocyte-derived TNF-like factor and recombinant TNF are cytotoxic for oligodendrocytes (28). Preliminary data suggest that LT is an even more potent inducer of damage to oligodendrocytes (unpublished observations). Thus, increased levels of these cytokines may contribute to both the primary demyelination and reactive gliosis that are characteristic of MS lesions.

\section{Acknowledgments}

The authors thank Drs. Labe Scheinberg, Barbara Geisser, and Charles Smith for providing clinical material for this study, and Earl Swanson for technical assistance. Supported by grants from the National Multiple Sclerosis Society (USA)(RG-1001-G7), and from the National Institutes of Health (NS-1 1920, NS-07098, and NS-08952). Dr. Selmaj is on leave of absence from the Department of Neurology, Medical Academy of Lodz, Lodz, Poland, and is a fellow of the National Multiple Sclerosis Society (FG-795-A-1)

\section{References}

1. Waksman, B. H. 1985. Mechanisms in multiple sclerosis. Nature (Lond.). 318:104-105.

2. Hofman, F. M., D. R. Hinton, K. Johnson, and J. E. Merrill. 1989. Tumor necrosis factor identified in multiple sclerosis brain. J. Exp. Med. 170:607-612.

3. Selmaj, K. W., and C. S. Raine. 1988. Tumor necrosis factor mediates myelin and oligodendrocyte damage in vitro. Ann. Neurol. 23:339-346.

4. Sternberger, L. A. 1986. Immunocytochemistry. John Wiley \& Sons, Inc., New York.

5. Poser, C. M., D. W. Paty, L. Scheinberg, W. I. McDonald, F. A. Pavis, G. C. Ebers, W. A. Sibley, D. H. Silberberg, and W. W. Tourtellotte. New diagnostic criteria for multiple sclerosis: guidelines for research protocols. 1983. Ann. Neurol. 13:227-231.

6. Raine, C. S. 1983. Multiple sclerosis and chronic relapsing EAE: comparative ultrastructural neuropathology. In Multiple Sclerosis. Pathology, Diagnosis and Management. J. F. Hallpike, C. W. M. Adam, and W. W. Tourtellotte, editors. Williams \& Wilkins Co., Baltimore, MD.
7. Gallo, P., M. G. Piccinno, L. Krzalic, and B. Tavolato. 1989. Tumor necrosis factor alpha (TNF alpha) and neurological diseases. Failure in detecting TNF alpha in the cerebrospinal fluid from patients with multiple sclerosis, AIDS dementia complex, and brain tumors. J. Neuroimmunol. 23:41.

8. Franciotta, D. M., L. M. E. Grimaldi, G. V. Martino, G. Piccolo, R. Bergamaschi, A. Citterio, and G. V. Melzi d'Eril. 1989. Tumor necrosis factor in serum and cerebrospinal fluid of patients with multiple sclerosis. Ann. Neurol. 26:787789.

9. Merrill, J. E., S. R. Strom, G. W. Ellison, and L. W. Myers. 1989. In vitro study of mediators of inflammation in multiple sclerosis. J. Clin. Immunol. 9:8496.

10. Beck, J., P. Rondot, L. Catinot, E. Falcoff, H. Kirchner, and J. Wietzerbin 1988. Increased production of interferon gamma and tumor necrosis factor precedes clinical manifestation in multiple sclerosis: do cytokines trigger exacerbations? Acta Neurol. Scand. 78:318-323.

11. Lieberman, A. P., P. M. Pitha, H. S. Shin, and M. L. Shin. 1989. Production of tumor necrosis factor and other cytokines by astrocytes stimulated with lipopolysaccharide or a neurotropic virus. Proc. Natl. Acad. Sci. USA. 86:63486352.

12. Chung, I. Y., and E. N. Benveniste. 1990. Tumor necrosis factor alpha production by astrocytes: induction by lipopolysaccharide, IFN-gamma, and IL1 beta. J. Immunol. 144:2999-3007.

13. Frei, K., Ch. Siepl, P. Groscurth, S. Bodmer, S. Schwerdeland, and A. Fontana. 1987. Antigen presentation and tumor cytotoxicity by interferongamma treated microglial cells. Eur. J. Immunol. 17:1271-1278.

14. Cuturi, M. C., M. Murphy, M. P. Costa-Gioma, R. Weinmann, B. Pertussia, and $G$. Trinchieri. 1987. Independent regulation of tumor necrosis factor and lymphotoxin production by human peripheral blood lymphocytes. J. Exp. Med. 165:1581-1594.

15. Ruddle, N. H., and R. Homer. 1988. The role of lymphotoxin in inflammation. Prog. Allergy. 40:162-182.

16. Old, J. L. 1990. Tumor necrosis factor. In Tumor Necrosis Factor: Structure, Mechanism of Action, Role in Disease and Therapy. B. Bonavida and G. Granger, editors. Karger, Basel, Switzerland.

17. Carswell, E. A., L. J. Old, R. C. Kassel, S. Green, N. Fiore, and B. Williamson. 1975. An endotoxin-induced serum factor that causes necrosis of tumors. Proc. Natl. Acad. USA. 72:3666-3670.

18. Pukel, C., H. Baquerizo, and A. Rabinovitch. 1988. Destruction of rat islet cell monolayers by cytokines. Synergistic interactions of interferon-gamma, tumor necrosis factor, lymphotoxin, and interleukin 1. Diabetes. 37:133-136.

19. Garrett, I. R., B. G. Durie, G. E. Nedwin, A. Gillespie, T. Bringman, M. Sabatini, D. R. Bertolini, and G. R. Mundy. 1987. Production of lymphotoxin, a bone-resorbing cytokine, by cultured human myeloma cells. N. Engl. J. Med. 317:526-532.

20. Cavender, D. E., D. Edelbaum, and M. Ziff. 1989. Endothelial cell activation induced by tumor necrosis factor and lymphotoxin. Am. J. Pathol. 134:551560.

21. Pober, J. S., L. A. Lapierre, A. H. Stolpen, T. A. Brock, T. A. Springer, W. Fiers, M. P. Bevilacqua, D. L. Mendrick, and M. A. Gimbrone Jr. 1987. Activation of cultured human endothelial cells by recombinant lymphotoxin: comparison with tumor necrosis factor and interleukin 1 species. J. Immunol. 138:33193324.

22. Shijo, K., S. Tsuda, T. Hayami, T. Asahi, and H. Kawaharada. 1989. Increase in permeability of human endothelial cell monolayer by recombinant human lymphotoxin. Biochem. Biophys. Res. Commun. 162:1431-1437.

23. Esparza, I., D. Mannel, A. Ruppel, W. Falk, and P. H. Krammer. 1987. Interferon gamma and lymphotoxin or tumor necrosis factor act synergistically to induce macrophage killing of tumor cells and schistosomola of Schistosoma mansoni. J. Exp. Med. 166:589-594.

24. Sica, A., J. M. Wang, F. Colotta, E. Dejane, A. Mantovani, J. J. Oppenheim, C. G. Larsen, C. O. C. Zachariae, and K. Matsushima. 1990. Monocyte chemotactic and activating factor gene expression induced in endothelial cells by IL-1 and tumor necrosis factor. J. Immunol. 144:3034-3038.

25. Kaushansky, K., V. C. Broudy, J. M. Harlem, and J. W. Adamson. 1988. Tumor necrosis factor-alpha and tumor necrosis factor-beta (lymphotoxin) stimulate the production of granulocyte-macrophage colony-stimulating factor, macrophage colony-stimulating factor, and IL-1 in vivo. J. Immunol. 141:3410-3415.

26. Selmaj, K. W., M. Farooq, T. Norton, C. S. Raine, and C. F. Brosnan. 1990. Proliferation of astrocytes in vitro in response to cytokines. A primary role for tumor necrosis factor. J. Immunol. 144:129-135.

27. Lachman, L. B., D. C. Brown, and C. A. Dinarello. 1987. Growth promoting effect of recombinant interleukin 1 and tumor necrosis factor for a human astrocytoma cell line. J. Immunol. 138:2913-2916.

28. Robbins, D. S., Y. Shirazi, B.-E. Drysdale, A. Lieberman, H. S. Shin, and M. L. Shin. 1987. Production of cytotoxic factor for oligodendrocytes by stimulated astrocytes. J. Immunol. 139:2593-2597. 